\title{
Hegel, Frente e Verso
}

\section{Nota sobre achados e perdidos em História da Filosofia}

Paulo Eduardo Arantes *

Resumo: este artigo visa mostrar as diferenças de leitura entre La patience du concept (1972) e 0 Avesso da Dialética (1988), dois livros em que Gérard Lebrun intenpreta e discute a filosofia de Hegel

Palavras-chave: dialética - hegelianismo - historia da filosofia

"Que a vida dessa faca se mede pelo avesso" João Cabral de Melo Neto

O que se descobre quando viramos do avesso a dialética hegeliana? Segundo Gérard Lebrun, nada de muito animador: tudo somado, uma estratégia cristã de culpabilização da existência, mais o seu cortejo de paixões tristes, a que no fundo resume o trabalho do negativo. Embora previsível, essa adesão por extenso ao anti-hegeliani.smo militante da Ideologia Francesa (alimentado no entanto com recursos próprios e nenhuma concessão à 
terminologia em voga) só se apresentou, pelo menos na forma acabada de um livro, em 1988 - justamente O Avesso da Dialética, publicado em São Paulo naquele ano. Até aí nada de mais, se não nos lembrássemos que quase cuas décadas atrás, mais precisamente em 1972, a dialética não tinha nenhum avesso que a incriminasse: ela era literalmente "imprenable". Refirome ao primeiro livro de Lebrun sobre Hegel, A Paciência do Conceito. Aqui a grande novidade. Visto de frente, o discurso hegeliano não encobria nenhum fantasma ideológico, nenhum apogeu metafísico ou ontoteológico etc. Todavia, dois anos antes, nada permitia antecipar tamanha reviravolta, pelo contrário predominavam as prevenções de costume: na sua grande tese (como se dizia então) sobre a Terceira Crítica, Lebrun não perdia ocasião de lembrar que o hegelianismo era mesmo uma teodicéia, que a confiança na presença de uma razão atuante na história só deixaria de ser a especulação de um visionário para se tomar a realidade cotidiana dos estados policiais etc. A lei do gênero assim ordenava: se o autor a ser explicado era Kant, Hegel nunca poderia estar certo, e vice-versa, como se veria no livro seguinte. Também não deve ter sido pequena a surpresa de seus admiradores brasileiros: os que tiveram a chance de acompanhar, durante a primeira metade dos anos 60, seus cursos na USP, sabiam muito bem que a aversão de Lebrun pela dialética era a bem dizer congênita, tão antiga e arraigada quanto os preconceitos da filosofia universitária francesa - como se sabe, um híbrido espiritualista de neo-kantismo e positivismo. Inútil lembrar que tamanha alergia se manifestava em exposições magistrais, como a aula histórica consagrada ao comentário da convicção hegeliana de que as feridas do espírito se curam sem deixar cicatrizes. Por certo os motivos anti-hegelianos de Deleuze, Derrida e Cia. já não tinham mais nada a ver com as implicâncias de um Brunschvicg e sucessores - como se sabe, entroncavam na fraseologia da transgressão, um veio até então subterrâneo e tardio do "modernismo" francês, um arco heteróclito que se estendia de Bataille a Tel Quel. Quanto a Lebrun, como lembrado, não precisava anunciar que estava em campanha contra o Logocentrismo ocidental e seus derivados, ou empenhado na formulação de uma filosofia da Diferença. Bastava seguir as regras de seu métier - o de um professor formado na escola francesa de filosofia -, deixando-se no entanto impregnar discretamente pelos ares do tempo. De qual- quer modo, embora partilhasse com a França intelectual do momento o ponto de honra que mandava maldizer da dialética em todos os quadrantes, o fato é que naquele ano de 1972 Lebrun resolveu não obstante contrariá-lo. Presumo que também por natural espírito de contradição, sem descartar entretanto o cálculo retórico de só confi mar mais adiante o credo reinante depois de fazê-lo confessar a opinião oposta. Um passe de armas que só mesmo a índole dissertativa de um gênero sem problemas facultava, mas não a qualquer um.

$\star \star \star$

A Paciência do Conceito é antes de tudo um notável exercício de desdogmatização de um sistema filosófico, além do mais executado, nada mais nada menos, na figura do mais dogmático sistema de todos os tempos. Sem muito exagero, são cento e cinqüienta anos de ilusões desfeitas por um dos mais inventivos livros da historiografia filosófica francesa. Simplesmente ficávamos sabendo que não existia "filosofia hegeliana" alguma, nem mesmo filosofia disso ou daquilo (História, Arte, Direito etc.) . Numa palavra, erradicando-lhe todo e qualquer resíduo afimativo, Lebrun reduzia o hegelianismo ao que lhe parecia ser o essencial, à Dialética, e esta, a uma espécie de revolução discursiva sem precedentes (ou melhor, havia um e logo saberemos qual é), uma "máquina de linguagem" especializada em pulverizar as categorias petrificadas, as fixações arcaicas do pensamento dito "representativo", encarnado no caso pelo famigerado (depois do Idealismo Alemão) Entendimento. Comprimidas por tal engrenagem, as significações correntes se punham a flutuar para finalmente confessar que no fundo não eram nada mesmo, a não ser um ninho de contradições cujo resultado se desmanchava no ar. Não havia doutrina portanto, nada a ensinar ou informar. A Dialética, no final das contas, nada mais era do que uma maneira de falar. Apenas isto, ou então um delírio, um conto de fadas. Esta a alternativa, de fato muito apertada, na qual Lebrun encerrou então o 
hegelianismo, no claro intuito de reabilitá-lo à contracorrente, embora remasse a favor dela. Aí todo o sal do episódio.

(Diga-se de passagem que, sendo o eixo do livro uma interpretação que pela primeira vez levava às últimas conseqüências a palavra de ordem hegeliana que decretava a absorção da Ontologia pela Lógica, seguia-se daí - que para muitos deveria ser uma revelação, a saber: que a Dialética não era nem poderia ser de modo algum uma outra Lógica, por definição superior, empenhada em rivalizar com - e no limite, desautorizar - uma forma de pensamento relegada então às tarefas mais corriqueiras do espírito. Só por essa tentativa, que poderia libertá-los de um cativeiro secular, a sociedade dos amigos materialistas da Dialética hegeliana deveria erguer um monumento a Gérard Lebrun, ainda que ele tenha retomado a palavra dada, pois afinal armara o livro para isso mesmo.)

De onde teria vindo a Lebrun a idéia tão insólita de apresentar a dialética como um simples modo de falar? (Aliás, não tão simples assim.) Quanto à inspiração mais remota, confiemos em sua tarimba profissional. Sendo a História da Filosofia um feixe de referências cruzadas sem antes nem depois, é possível que o trabalhasse certa reminiscência de Aristóteles que não soubesse onde encaixar, justo na primeira hora em que procurava um socle para a dialética hegeliana. Fosse esta última encarada como a "dialética superior do Conceito" (como se exprimia Hegel acerca do momento positivo-racional da exposição especulativa), e o caminho mais natural das remissões em circuito fechado conduziria à visão sinóptica de Platão, onde se recobriam por inteiro Dialética e Ciência. Mas no caso da dialética propriamente dita, seu persistente "negativismo" não a aparentava à recusa aristotélica de conceder à dialética - desfigurada pelo amálgama platônico mais do que um saber negativo? Inversamente, aquele poder que Aristóteles The reconhecia, de enfrentar os contrários sem o apoio de definições prévias nem a promessa de um fundamento futuro, não parecia anunciar Hegel expondo o caráter antinômico das determinações finitas numa espécie de terra de ninguém, onde o Entendimento perdia o pé e a Razão ainda não chegara? Não se pode descartar a hipótese de que à vista de tal analogia, a primeira sugestão lhe tenha vindo da leitura do livro de Aubenque, Le Problème de l'Être chez Aristote, de 1962. É que a certa altura do livro (mais precisamente à p. 293), Aubenque definia a dialética aristotélica como uma façon de parler, cuja força libertadora the advinha da desenvoltura com que se movia num domínio situado muito além do reino das essências estáveis (como se diz em linguagem dissertativa) - por isso os homens podiam se entender mesmo quando não falavam de nada. - É bem possível que para essa ident ificação surpreendente não tenha contribuído pouco uma outra lembrança, a de um velho livro de Jean Hyppolite sobre Hegel, Logique et Existence, todo ele centrado também na absorção especulativa da Ontologia pela Lógica e na conseqüiente liberação de uma linguagem inédita, em condições de substituir o discurso-sobre pelo vir-a-ser do sentido em pessoa, um processo de explicitação de significaçães ao témino do qual encontrava-se igualmente abolida a transcendência de um suposto referente separado. Assim, de comparação em associação, Lebrun acabou se defrontando com a evidência da natureza discursiva da dialética, arrematada todavia pela conclusão radical que era preciso tirar: certo, apenas ummodo de falar, mas por isso mesmo livre da obrigação (metafísica) de falar sobre alguma coisa. Sem a menor dúvida, um verdadeiro achado, mas os achados em História da Filosofia são logo perdidbs. Não dostante ser muito bom, o livro de Hyppolite era apenas uma excelente fonte de dissertações. Quanto a Aubenque, sua redescoberta da dialética (negativa) de Aristóteles vinha a ser um sintoma a mais da errância (sic) heideggeriana que lhe servia de horizonte e cuja retórica meditativa da perplexidade pela perplexidade não era por certo do gosto do nosso Autor. O que fazer? Por que não se deixar levar pelo timbre ultramoderno daquela fómula? Pois ela não sugeria finalmente que a dialética hegeliana deslizava para o coração da atualidade? Impregnado pelas linhas de força do momento, Hegel voltava a ser um filósofo legível.

Outras peças do quebra-cabeça no qual encaixar este primeiro achado proveniente dos guardados da História da Filosofia, vinham igualmente de casa. Em primeiro lugar, do método historiográfico preconizado pela referida Escola Francesa, segundo o qual o significado de um sistema filosófico permaneceria letra morta caso não desconsiderássemos a intenção doutrinária que o animava. Compreende-se que o exercício continuado desse método suspensivo tenha predisposto seu usuário a encarar raciocínios que não lhe diziam mais nada como outros tantos discursos enrolados sobre si 
mesmos. Lebrun por certo não ignorava o que havia de artifício nessa decantação mas acabara de constatar - relendo Kant dois anos antes - que a partir da obra crítica deste último a filosofia mudara a tal ponto de registro que a consideração meramente arquitetônica poderia ocupar sem violência o primeiro plano, pois de direito já não havia mais nenhuma verdade a ensinar. Noutras palavras, constatara que a historiografia dita estrutural e a assim chamada autonomia do discurso filosófico revelada por Kant tinham a mesma idade, entendendo-se no caso por autonomia a dieta muito magra de uma disciplina concernida exclusivamente pela observação de seu próprio funcionamento. (Um regime autárquico que Husserl levará ao paroxismo.) Por que não estender essa reviravolta até Hegel? Lebrun não hesitou: assim como a Crítica Kantiana ocupara o lugar da Teoria, do mesmo modo o foco do discurso hegeliano só poderia estar na Dialética, por sua vez decididamente negativa e intransitiva.

Por outro lado, também deve ter pesado muito na heresia de Lebrun algumas certezas herdadas da tradição epistemológica local - o outro pilar da filosofia universitária francesa -, abafadas durante a temporada existencialista de caça ao "concreto", ao "vivido" etc. A reação acadâmica, a que no fundo se resumia a maré estruturalista, trouxe de volta antigas distinções, como a sempre assinalada diferença epistemológica entre objeto de conhecimento e objeto real, convicção tão entranhada a ponto de reunir sob o mesmo programa o respeitável Prof. Gilles-Gaston Granger e o "ideólogo" Louis Althusser. Entre outras coisas, ambos convergiam na rejeição do "mito especular da visão", como se referia Althusser aos esquemas perceptivos que sustentavam a noção clássica de conhecimento. Comentando certa vez (numa resenha de 1969, para ser preciso) a segunda edição do livro de Granger, Pensée Formelle et Sciences de l'Horme, Lebrun se engajaria por seu turno na luta contra esse mesmo mito (realimentado pelos melhores amigos do "vivido", os fenomenólogos) da homogeneidade entre formas percebidas e objetividades construídas, responsável pela confusão antiquada entre saber científico e "teoria". Um ano depois, essa evidência da epistemologia francesa reapareceria no seu lugar de origem, segundo Lebrun, a crítica kantiana da ilusão "teórica" que vitimara as metafísicas do passado. Mais um pouco e reencontramos aquela mesma evidência convertida agora na conclusão (que Althusser sem dúvida aprovaria) de que o assim chamado problema do conhecimento nada mais é do que uma construção ideológica (mais exatamente, uma miragem induzida por uma concepção instrumental da linguagem), ilusão que acompanha todo ato de referência a conteúdos que se trataria então de alcançar e compreender: esse o passo dado pelo hegelianismo enquanto máquina discursiva de triturar significações finitas. Ou melhor, o passo surpreendente dado na verdade por Lebrun, emparelhando a dialética hegeliana aos últimos desdobramentos da epistemologia francesa - o que aliás Althusser fizera com Marx.

Mas ainda faltava o principal, sugerir os antecedentes vanguardistas da revelação - anunciada em sua intensidade filosófica máxima pelo discurso hegeliano na figura da negação indeterminada em que se resolvia a dissolução polêmica das categorias do Entendimento - que representava a descoberta de que um tal modo muito pouco filosófico de falar não dizia, nem poderia dizer, rigorosamente nada. Assim sendo, a última palavra caberia ao novo surto "modernista" francês, que irrompera no início dos anos 60 e cuja plataforma a bem dizer se concentrava no seguinte ponto doutrinário: tudo se passa como se o processo cultural no seu conjunto girasse em torno de uma experiência-limite, no caso a experiência abissal dos limites da linguagem, mais exatamente de uma linguagem irredutível que, sem jamais se calar, "ne dit rien (...) qui soit". Desta fonte originária brota a Literatura, espécie de ato puro voltado inteiramente para o enigma do seu nascimento, que nada designa além de si mesmo, um ato marcado portanto pela mais absoluta intransitividade. Dissipada a ilusão referencial, ficava claro finalmente que o verdadeiro assunto da Literatura sempre foi a própria Literatura. Aliás ninguém entra em Literatura (o galicismo diz tudo) porque tem algo a dizer, mas para enunciar a experiência-limite de que justamente já não há mais nada a dizer. Essa fraseologia vinha de longe, pelo menos (e noutra chave) desde os tempos em que Malraux via nas telas de Manet pintura sobre pintura. Bataille e congêneres acrescentaram-lhe o pathos sublime da transgressão. Barthes e a Nouvelle Critique forneceram-lhe um suplemento científico, cabendo enfim a Foucault redigir a Suma desse último sobressalto "modernista", Les Mots et les Choses. Arrematando os momentos de apogeu retórico do livro com breves incursões à região mais remota 
em que a linguagem reencontra o seu ser bruto, Foucault dava a entender que também estava balizando uma espécie de história subterrânea de invenção da Literatura, cujo marco zero recuaria até Mallarmé para depois saltar até a linha de frente da mais perfeita experimentação telquelista - derradeiro pétard mouillé de uma vanguarda há tempo desativada, como atestam modelos inverossímeis como um Raymond Roussel ou tal página retardatária de Maurice Blanchot. Mas naquele derradeiro arranco contava menos a inviabilidade artística de tais dbras terminais do que as alegações que deveriam ilustrar, a começar pelo livro-manifesto de Foucault acerca do nada semântico em torno do qual girava o discurso literário. Deixando-se envolver pelo panorama entreaberto por Foucault (verdadeiro mito de origem acerca da preeminência moderna da forma), compreende-se que Lebrun, fechando o círculo, tenha finalmente atinado com o destino que esperava seu tema. Afinal as leituras hegelianas de Mallarmé não estavam abundantemente documentadas? Pois agora ficaríamos sabendo que a palavra poética que enunciava " 1 'absente de tous bouquets", minando a presença plena do mundo, tinha a mesma idade arqueológica do contradiscurso hegeliano. Assim, sem precisar forçar muito a nota, Lebrun foi empurrando a autonomia do discurso filosófico moderno, um discurso sem território personificado superlativamente pela dialética hegeliana - como antes, de maneira mais branda pela livre Reflexão das filosofias transcendentais -, até os confins da Literatura que por definição (francesa) só vem ao mundo uma vez rompida a barreira ilusionista da figuração. Quem diria? Hegel no álbum de família da Ideologia Francesa. Antes de tirar o chapéu, admiremos também, na sua justa e espontânea ambivalência, o humor (nunca se sabe até que ponto calculado) dessa reconciliação intempestiva.

$\star \star \star$

Como ficamos? Sendo a História da Filosofia aquilo que se sabe, não espanta que num certo sentido continuássemos na mesma. A demonstração de que a dialética hegeliana tinha a mesma idade discursiva do momento filosófico francês - cuja certidão de nascença não dbstante era a ruptura espalhafatosa com as fadaises da dialética humanista do período anterior esgotava-se em si mesma. O paradoxo valia por certo como prova de atualidade, mas como todos nadavam a favor da corrente, o assunto estava encerrado. Nem mesmo se chegou a colocar a questão do que fazer com a dialética assim entendida. Numa palavra, uma gageure sustentada de ponta a ponta, porém sem futuro.

Dezesseis anos depois uma reviravolta do pró ao contra? Quanto ao fundo, de modo algum. Como ficou dito, todo o mal que a nova inteligência pensava da dialética e seus derivados, Lebrun também pensava, simplesmente decidira apresentar o seu requisitório apenas depois de expô-la em funcionamento na força da idade, aliás atualíssima. Pode-se por certo lastimar, mas não seria correto falar numa simples recaída a propósito desse retorno à rotina do Hegel cristão e metafísico. De resto, fora anunciado ao longo do livro, embora discretamente, que se estava reservando a questão espinhosa do Sistema - como uma polêmica em princípio sem a menor intenção de ciência podia ser ao mesmo tempo a exposição do sistema-daverdade? - para um estudo posterior, que sabemos qual é e já devia estar quase pronto naquela mesma época. Além do mais, ficara acintosamente sem resposta a mais corriqueira abjeção (coisa que o Prof. Lebrun não poderia fingir ignorar por muito tempo) : qualquer estudante sabe que Hegel não passara a vida fechado em copas (ou cuidando exclusivamente de questões de método, o que dá no mesmo), mas opinava sistematicamente sobre tudo - se havia alguém que de fato falara sobre Deus e sua época, fora ele mesmo. Chegaria portanto o momento de redefinir o nada sobre o qual a dialética hegeliana também baseara a sua causa, e no qual tantos leitores otimistas apostaram todas as suas fichas.

Para começar, voltando a distinguir o que Hegel nunca confundira, apenas enigmaticamente articulara, o momento negativo da dialética e o "positivo-racional", que vem a ser a instância final do arremate especulativo. o cenário é familiar: nada deu tanta dor de cabeça à esquerda hegeliana, interessada em isolar o Método, este sim revolucionário, do Sistema conservador, quanto essa encruzilhada desconcertante. Ora, a primeira coisa que se aprende na escola (francesa de história da filosofia) é a evitar essas 
mutilaçães. Mesmo assim são essas as cartas que Lebrun gosta de baralhar. À primeira vista, no que mais se aplicava o livro de 72 senão em flertar com aquele lugar-comm, expurgando o lixo doutrinário e retendo apenas a lição do Método? Por pura provocação, está claro. Em lugar da "álgebra da revolução" com a qual sonhava, depois da alemã, a linhagem radical da intelligentsia russa oitocentista, uma subversão sintática que em princípio desbancava as promessas da primeira, um abalo sísmico propagando-se através da escrita de vanguarda e outros descentramentos - em lugar de Heine e Alexander Herzen, Philippe Solers e Kristeva. Torno a repetir que Lebrun subscrevia o credo parisiense da revolução pela linguagem sem no entanto jamais transigir com as facilidades do jargão que o alimentava. Limitava-se a aclimatar aquela substituição de radicalismos aos hábitos da escola mencionada, acalmando as consciências agradecidas pelo aggiornamento sem concessões.

Feita a ressalva depois de registrada a sensação familiar de que nosso Autor poderia estar ressuscitando - por certo com más intenções - uma veIha tábua de salvação do pensamento progressista, voltemos à manobra de alto bordo que consiste em devolver o hegelianismo à retaguarda do Ocidente depois de uma curta porém necessária temporada nos postos avançados da vanguarda. Como ficou dito, a aparente marcha à ré precisava primeiro distinguir para depois fundir num só bloco a cara feia do verdadeiro Hegel, advogado das forças reativas, das coisas de não, como diria o poeta. Atenção portanto: o hegelianismo não se recuz à dialética, sua última palavra é positiva e proferida na hora especulativa da totalidade reconstruída; e mais, é justamente nessa hora grave da "teologia integral" - ou do mais deslavado integrismo - que se fecha o ciclo negativo das dialéticas aniquiladoras que o filósofo especulativo nos fez percorrer. Não foi certamente por acaso que Lebrun - embora na forma pós-datada de uma revolução discursiva - trouxe para o primeiro plano o lado "exercício cético e nililizante" da dialética, correndo o risco sem dúvida calculado de estender indevidamente ao conjunto do pensamento hegeliano a patologia da negação indeterminada, que este último isolara como quem isola um vírus desde a Introdução da Fenomenologia. Desnecessário frisar a esta altura que Lebrun, melhor do que ninguém, sabia que a dialética negativa, como o próprio Hegel denominava a existência bruta dela, não era toda a Dialética, que a negação enfim comportava sempre uma segunda negação e que esta, sem transformar a primeira numa miragem, tinha o condão de converter perdas em ganhos. Daí o coup de théât re premeditado por Lebrun precisar apresentar-se como a súbita revelação de um contágio progressivo, o vírus do niilismo inoculado pela dialética alastrando-se até contaminar todo o sistema. A rigor, as etapas da metamorfose da dialética, a demonstração passo a passo de que o avesso de um discurso de vanguarda que por isso mesmo não dá em nada é justamente uma estratégia cristã nadificante, não se desenrola sob nossos olhos: ela já se consumou quando abrimos o segundo volume. Sobram quando muito alguns alinhavos da alta costura que é uma verdadeira dissertação francesa, do tipo: o que podia parecer subversão, era na verdade a transfiguração, a manifestação, a explicitação etc., de um princípio, de uma totalidade etc., de cujos agissements não se pode evidentemente esperar nada de bom etc. Convenhamos que o arrombamento dessa enorme porta aberta é o preço pago pela amputação drástica a que o primeiro livro devia sua força inventiva. Não é esta que falta ao segundo, até porque o que não falta nele são argumentos novos em defesa de uma tese tradicional. O mais atraente deles é o que melhor ilustra essa inversão de sinal do "niilismo" por trás dos bastidores - pois afinal é isso o que se passa de um livro ao outro.

Mesmo para um leitor de boa vontade, nada mais desconcertante e acabrunhador do que a filosofia hegeliana da história. Por outro lado, não é a história-do-mundo a viga mestra da tradição hegeliana, a própria máquina do mundo em pessoa - e uma das maiores fixações doutrinárias do marxismo filosofante, tanto assim que embora the reconheça o fundo de fabulação especulativa não consegue se desvencil lhar da tentação recorrente de reeditála? Admiremos novamente o que ainda pode a história (francesa) da filosofia, nas mãos de um dos seus maiores mestres: Lebrun não só encontrou uma fórmula que especifica aquele mal-estar, mas consegue juntar as chas pontas do seu argumento contra-hegeliano enquanto martela a idéia fixa de que falávamos, servindo sem querer à causa dos que gostariam de se livrar daquele atraso de vida, mas não a troco de sucedâneos. Mitologia por mitologia, ao que parece ficamos na mesma trocando a Historia ancilla theologiae 
(de Santo Agostinho a Hegel) pela "inocência do devir" que em princípio ela teria recalcado, ou o Espírito-do-Mundo, pelo Eterno Retorno do Mesmo. É bem verdade também que ao dinamitar a Weltgeschichte Lebrun dá a boa notícia para um público blasé, acostumado a fazer pouco das filosofias da história desde os tempos em que Lévi-Strauss encarou Sartre no último capítulo da Pensée Sauvage. - o que mais constrange, sobretudo quem ainda não tem a sensibilidade embotada do profissional, nas Lições sobre a Filosofia da História Mundial não é a habitual complicação conceitual, neste caso até bem rara, mas a sensação desoladora de estar lendo um livro que já nasceu velho, não só quando comparado com o que havia de mais vivo na historiografia da época (pensemos nos historiadores franceses que estrearam sob a Restauração), mas no que sabia qualquer jornalista inglês ou francês (ainda mais quando socialista) acerca dos grandes temas da atualidade, entre eles a Revolução de Julho, abordado nas últimas páginas das Lições, mesmo descontando-se o fato de que se tratava apenas de um professor de filosofia, ainda por cima alemão. Sem tomar esse rumo, muito ao contrário, Lebrun corta pela raiz a possibilidade de tais comparações, enfatizando em contrapartida a estranheza do discurso hegeliano sobre a História: nem narrativo, nem explicativo, em nenhum momento essa escrita de estatuto epistemológico indefinido pretendeu rivalizar seja com a crônica tradicional, seja com o conhecimento histórico propriamente dito, fazer da História-do-Mundo uma "super-intriga" ou apresentar-se como um saber superlativo. Completemos: os grandes enunciados desse discurso também operam por assim dizer no vazio, mas como não se referem a nada, não levam a nada. Só que agora esse nada epistemológico - no qual se detivera, sem nomeá-lo por extenso, a Paciência do Conceito - toma corpo numa cons-telação de "formas meio-conceituais meio-imaginativas" chamada Weltgeschichte, numa palavra, ganha uma significação precisa, ou melhor, esse nada com sinal trocado é a sombra projetada por uma espécie de busca filistina do "sentido" a todo custo (igual a segurança). Produção desenfreada de "sentido" enquanto justificação (no caso, do acontecimento) : esse o traço mais saliente do "niilismo" que Lebrun traz de volta, invertendo-lhe o sinal, como se disse. O núcleo do argumento reunificado poderia então ser parafraseado mais ou menos como segue. Assim como a manifestação do
Absoluto - o Sistema-da-Verdade que a redescoberta da dialética negativa não poderia pura e simplesmente cancelar - é o avesso disciplinador (na acepção que o termo adquiriu com Foucault) do discurso ultra-iluminista em que as determinações tradicionais do pensamento figurativo confessam a própria nulidade, do mesmo modo a História Mundial, que nada edifica e tudo devasta (não nos esqueçamos de que algumas interpretações do conceito hegeliano de história principiam por uma meditação sobre as ruínas), também produz um sentido superior acumulando escombros, sobras da história, montes de tijolos recobertos por um "sentido" que escolheu o sofrimento como o seu portador.

O achado não está por certo na ressurreição dos temas teológicos. Onde então? Salvo engano, num conjunto de aproximações que dispensam tais referências, e por isso dão o que pensar. Se é fato que a Weltgeschichte hegeliana, longe de ser o sal da terra, é a exposição completa da "atividade nadificante" do Espírito-do-Mundo, por que não retardar um pouco o desfecho previsível e sondar ainda a quente o terreno recém desobstruído? No magma de formas "meio-conceituais meio-imaginativas" em que se decompõe o enigma especulativo do Espírito-do-Mundo, sobretudo caracterizado agora em sua atuação de maneira tão moderna, deve haver certamente algo mais do que Teologia, Primeiro Motor Imóvel, a culpabilização do devir inocente condenado a justificar-se etc. - Inútil prosseguir pois vejo que estou simplesmente pedindo o impossível a Lebrun, que retroceda ao primeiro movimento de sua demonstração: imagino que o autor de A Paciência do Conceito, mesmo pensando na revelação de Deus como Espírito, não anunciaria tão rapidamente que só esta megaentidade (além do mais grega de nascença) se manifesta "devastando e destruindo". Mas isto já é uma outra história.

Abstracts: This article discusses interpretative differences between Iebrun's La patiente du concept (Paris, 1972) and O Avesso da Dialética (São Paulo, 1988), two books dedicated to the lecture of Hegel's philosophy.

Key-words: dialectic - hegelianism - history of philosophy 